\title{
Poverty Alleviation Strategies in the Russian Arctic Zone Regions
}

\author{
Rudenko Dmitry Y. \\ Tyumen State Academy of World Economy, Management and Law; Tyumen State University, Tyumen, Russia \\ Email:drudenko@inbox.ru \\ Pogodaeva Taisia V. \\ Tyumen State University, Tyumen, Russia \\ Email: taissia2001@mail.ru \\ Didenko Nikolay I. \\ St. Petersburg State Polytechnical University; Russia \\ Email: nikolay@mail.ru
}

\section{Doi:10.5901/mjss.2015.v6n1p32}

\section{Abstract}

The official approach to the definition of poverty is analyzed and its main problems are shown based on the case study of Russian Arctic regions. In order to identify a comprehensive picture of poverty in the regions, indicators that characterize this phenomenon from monetary viewpoint are compared. The paper proves the need to classify a range of strategies to reduce poverty in the Russian Arctic zone regions. The findings reveal that a sensible poverty reduction strategy should focus both on the quantity of growth (that is, on the achievement of a high growth rate) and on the quality of growth (that is, on who benefits from that growth). We calculated the growth-inequality trade-off indices under the assumption that the per capita income follows a two-parameter lognormal distribution. We used the interpolation method as an analytical tool, supposing the selection of an empirical distribution curve for the given income ranges by the OLS method and the calculation of the necessary values of the poverty based on the selected curve. The research demonstrates that the initial level of economic development and income inequality matters for the alleviation of poverty. It was proved that the poverty indicators in the relatively rich regions and regions with high inequality are more sensitive to changes in distribution than changes in average income. At the same time, the poverty level in the regions with low income and relatively low inequality stronger responsive to economic growth than to changes in an inequality.

Keywords: poverty, inequality, poverty alleviation strategy, regions of Russia, Arctic zone.

\section{Introduction}

The prevalence of the official poverty in the Russian regions ranged from 6.9 to $35.4 \%$ in 2013. The lowest proportion of the poor in 2013 had the Yamalo-Nenets Autonomous Okrug (6.9\%), the Tatarstan Republic (7.2\%) and Belgorodskaya oblast (7.6\%), and the maximum level was maintained in Kalmykia (35.4\%) and Tyva (35.1\%). The dynamics of the population with incomes below the subsistence level shows a stable downward trend, but the dynamics of poverty, defined by the European methodology, is not so clear and shows that on average, one-third of the population are relatively poor. The lowest proportion of the relatively poor in 2013 had the Tver Oblast (23.6\%) and Republic of Altai (24.5\%), and the maximum level was maintained in Moscow (38.8\%) and Saint-Petersburg (34.3\%). Authors' retrospective analysis shows significant differences in levels of poverty between Russian regions; a high degree of interregional and intraregional income inequality; a close relationship between poverty rates, per capita incomes and inequality measures; a striking contrast in poverty indicators, calculated by different methods - absolute and relative.

While some regions have been successful in reducing poverty within the past decade, the poverty continues to be a persistent problem in many others. A sustained high economic growth in almost all regions has significantly reduced absolute income poverty, but in many of the high-growth regions, the growth has been associated with a rising inequality (which can retard the impact of the growth on poverty) so that the poverty impact of growth has been slower than it could have been (Fig. 1). As a consequence, the impact of inequality on the poverty alleviation has received renewed attention given that poverty reduction will be slower in regions that experience a rising inequality as well as in regions with a high 
initial inequality.

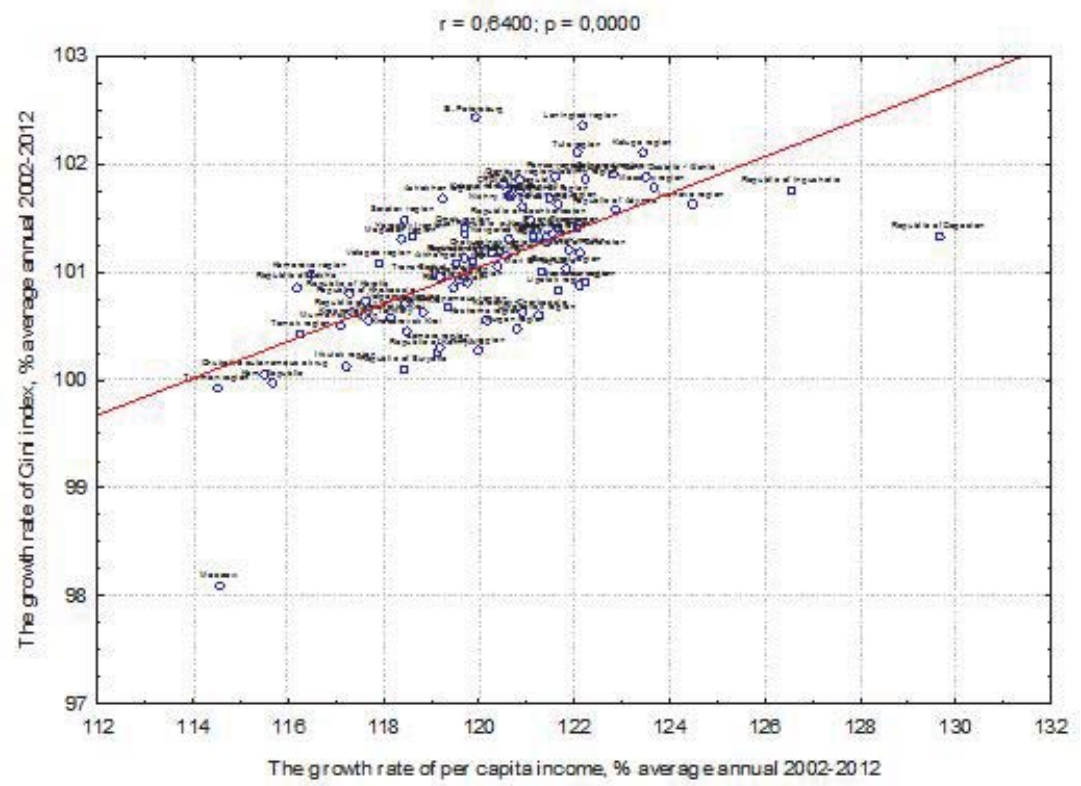

Figure 1. The interdependence of economic growth and changes in income inequality in Russian regions, 2002-2012.

The inequality has intensified during the period of economic growth. This is a consequence of a very uneven distribution of "fruits" of economic growth and revenues from high commodity prices to different social groups and regions. As a result, the rich get richer and the poor - relatively poorer.

According to the Russian President's Decree \#296 of $2^{\text {nd }}$ of May 2014 the land areas of the Russian Arctic Zone include the territory of the Murmansk Oblast, Nenets Autonomous Okrug, Yamal-Nenets Autonomous Okrug and Chukotka, as well as some municipality territories of the Komi Republic, Republic of Sakha (Yakutia), Krasnoyarsk and Arkhangelsk Oblast. Since the quality of municipal statistics in Russia is very poor, we will compare the regions as a whole. Russia's Arctic has mainly raw specialization and creates the industrial basis for country's social and economic development. The Arctic zone creates about 5\% of GDP, but only 1.66\% of total Russian population lives there. As a result Arctic regions have one of the highest GRP per capita values and the lowest monetary absolute poverty measures in Russia (Table 1).

Table 1. The official poverty measures, the proportion of people with money income below the subsistence minimum, $\%$

\begin{tabular}{|lcccccccccc|}
\hline & 2000 & 2005 & 2006 & 2007 & 2008 & 2009 & 2010 & 2011 & 2012 & 2013 \\
\hline Yamal-Nenets Autonomous Okrug & 11.1 & 8.4 & 6.8 & 6.5 & 6.2 & 7.4 & 7.3 & 7.4 & 6.4 & 6.9 \\
Nenets Autonomous Okrug & 37.9 & 9 & 8 & 5.7 & 5.6 & 7.3 & 7.5 & 7.7 & 6.5 & 7.9 \\
Chukotka & 50.1 & 15.1 & 14.2 & 13.3 & 12 & 11.9 & 10.3 & 9 & 7.7 & 9.3 \\
Murmansk Oblast & 24.9 & 19.1 & 17.4 & 14.6 & 13.8 & 13.5 & 13.2 & 13.6 & 11.1 & 11 \\
Russia & 29 & 17.8 & 15.2 & 13.3 & 13.4 & 13 & 12.5 & 12.7 & 10.7 & 11 \\
Komi Republic & 26.3 & 14.9 & 14.6 & 13.8 & 15.1 & 16.5 & 15.6 & 16.3 & 13.4 & 14 \\
Arkhangelsk Oblast & 33.5 & 17.5 & 17.2 & 15.9 & 14.4 & 13.6 & 14 & 14.4 & 13.2 & 14.1 \\
Krasnoyarsk Oblast & 24.4 & 21.4 & 19.2 & 15.8 & 16.2 & 17.7 & 17.9 & 18.1 & 15.6 & 15.7 \\
Yakutia & 28.3 & 20 & 18.9 & 20.3 & 19 & 19.6 & 19 & 18.6 & 16.7 & 16.7 \\
\hline
\end{tabular}

As we can see from the Table 1, the lowest poverty measures are in the north regions of Russia. We can also observe an impressive drop in poverty measures, especially in Chukotka from 50.1\% in 2000 to $9.3 \%$ in 2013. A growth of the nominal monetary per capita income was observed in all Arctic regions during the period of 2000-2013. However, in real terms the growth of income was not as impressive as in nominal terms; compared with 2000 the income increased by more than 1.93 times in Murmansk Oblast (the loser) and 6 times in Nenets Autonomous Okrug (the champion). 
Table 2. The real disposable monetary income of the population, growth rate, $\%$

\begin{tabular}{|lcccccccccc|}
\hline & 2000 & 2005 & 2006 & 2007 & 2008 & 2009 & 2010 & 2011 & 2012 & 2013 \\
\hline Yamal-Nenets Autonomous Okrug & 119.5 & 101 & 108.8 & 110.8 & 110.6 & 92.3 & 98.8 & 105.2 & 110.6 & 102.7 \\
Nenets Autonomous Okrug & 137.8 & 92.1 & 113.4 & 129.2 & 112.7 & 89.1 & 101.4 & 98.4 & 110.8 & 101.5 \\
Chukotka & 98.5 & 117.3 & 107.2 & 104.4 & 105.2 & 91.1 & 106 & 109.5 & 105.9 & 95.2 \\
Murmansk Oblast & 116.7 & 109.5 & 110.8 & 109.5 & 107 & 98.9 & 98.5 & 96.7 & 107.6 & 104.7 \\
Russia & 113.4 & 111.7 & 114.1 & 113.1 & 103.8 & 101 & 105.4 & 101.1 & 105.8 & 103.7 \\
Komi Republic & 117.2 & 107.4 & 107.1 & 108.9 & 99.6 & 95.5 & 103.1 & 97.5 & 106.1 & 98.9 \\
Arkhangelsk Oblast & 120 & 113.5 & 110.3 & 109.2 & 111.2 & 103.3 & 102.8 & 100.5 & 104.3 & 106.4 \\
Krasnoyarsk Oblast & 115.9 & 107.5 & 112.9 & 121.9 & 110 & 96.2 & 100.8 & 102.7 & 104.6 & 102.9 \\
Yakutia & 105.3 & 105.8 & 106.1 & 105.1 & 108.6 & 101.4 & 102.9 & 103.4 & 105.9 & 101.8 \\
\hline
\end{tabular}

The decline in revenues in almost all Arctic regions during the crisis was more notable than that general in Russia. According to the official data, the real disposable monetary income of the population in above regions in 2009 decreased by $10.9 \%$ in Nenets Autonomous Okrug and by $1.1 \%$ in Murmansk Oblast. At the same time, generally in the country the decline in the income of the population was overcome by the end of 2009 and the annual dynamics was positive (1\%), the positive dynamics was also observed in Arkhangelsk Oblast and Yakutia.

If we compare Table 1 and Table 2 we can observe that poverty measures increased in all Arctic regions during 2013 except for Murmansk Oblast, where the official poverty rate decreased by $0.1 \%$. We can explain the increase in poverty in Chukotka and Komi Republic by the decrease of real incomes, but what is the reason for poverty growth in the remaining regions?

Table 3. The relative poverty measures in the Arctic regions of Russia, \%

\begin{tabular}{|lcccccccc|}
\hline & 2006 & 2007 & 2008 & 2009 & 2010 & 2011 & 2012 & 2013 \\
\hline Yamal-Nenets Autonomous Okrug & 33.56 & 34.29 & 34.29 & 33. & 32.75 & 32.62 & 33.6 & 33.14 \\
Nenets Autonomous Okrug & 34.81 & 36.76 & 37. & 34.16 & 34.29 & 33.77 & 34.1 & 33.56 \\
Chukotka & 27.67 & 28.31 & 28.7 & 28.62 & 29.61 & 30.36 & 30.9 & 29.9 \\
Murmansk Oblast & 26.64 & 28.1 & 28.35 & 28.58 & 28. & 27.59 & 28.35 & 28.35 \\
Komi Republic & 32.4 & 33. & 32.54 & 31.6 & 31.52 & 31.11 & 31.6 & 31. \\
Arkhangelsk Oblast & 24.95 & 25.64 & 26.64 & 27.17 & 26.68 & 26.49 & 27.2 & 26.6 \\
Krasnoyarsk Oblast & 30.36 & 33. & 32.75 & 32.13 & 32. & 32. & 31.6 & 31.52 \\
Yakutia & 28.84 & 28.7 & 29.2 & 28.84 & 28.84 & 29.12 & 29.3 & 29.3 \\
\hline
\end{tabular}

The poverty in the Arctic regions is a problem of high inequality and its incidence cannot be drastically reduced in the short term without a radical reduction of inequality (see Table 3). The reduction of poverty should be among the priority directions of the state policy. To accelerate poverty alleviation, it is thus crucial to create favorable conditions of sustainable social and economic development and to devise poverty reduction strategies at the national, regional and local levels. It is necessary to formulate the vision and goals within these strategies; to plan all the necessary actions and to define and allocate resources for their implementing; to differentiate powers of federal, regional and local authorities; to reveal groups of the population with the highest risk of poverty, and also the most numerous groups of the poor population and a form of their social support.

In spite of numerous attempts of poverty alleviation strategies implementation analysis, the problem did not disappear. Russia has not developed its own national poverty alleviation strategy or even a program as a framework for poverty reduction as how some CIS countries (Azerbaijan, Kazakhstan, Tajikistan, Uzbekistan) have already done. The all-Russian hearings on "The poverty reduction strategy in Russia" conducted by the Public Chamber of the Russian Federation in 2006 was another step in this direction. Paragraphs 1 and 2 become one of the recommendations made during the discussion: "To consider the elimination of poverty as one of the priority tasks and the main efficiency indicator of social policy in the Russian state" and "To recognize the necessity of the social development strategy and the social policy concept of the Russian Federation implementation, which includes the formation of poverty reduction strategy in the Russian Federation". More than eight years have passed, but the Russians have not seen the adopted concept yet. Some subjects of the Russian Federation are developing their own regional programs aimed at poverty reduction. In this case the relevance of the theme is still very high - multidimensional poverty remains one of the main obstacles to increase the birth rate and to solve the demographic problem of dying Russia. The objective of this paper is to identify a 
comprehensive picture of poverty in Russia's Arctic zone regions and to classify a range of poverty alleviation strategies there. The study may be significant for federal, regional and local authorities advancing measures for socio-economic development of territories.

\section{Methodology}

We have formulated the principles of the poverty alleviation strategy formation, and suggested the mechanism of its implementation (Fig. 2).

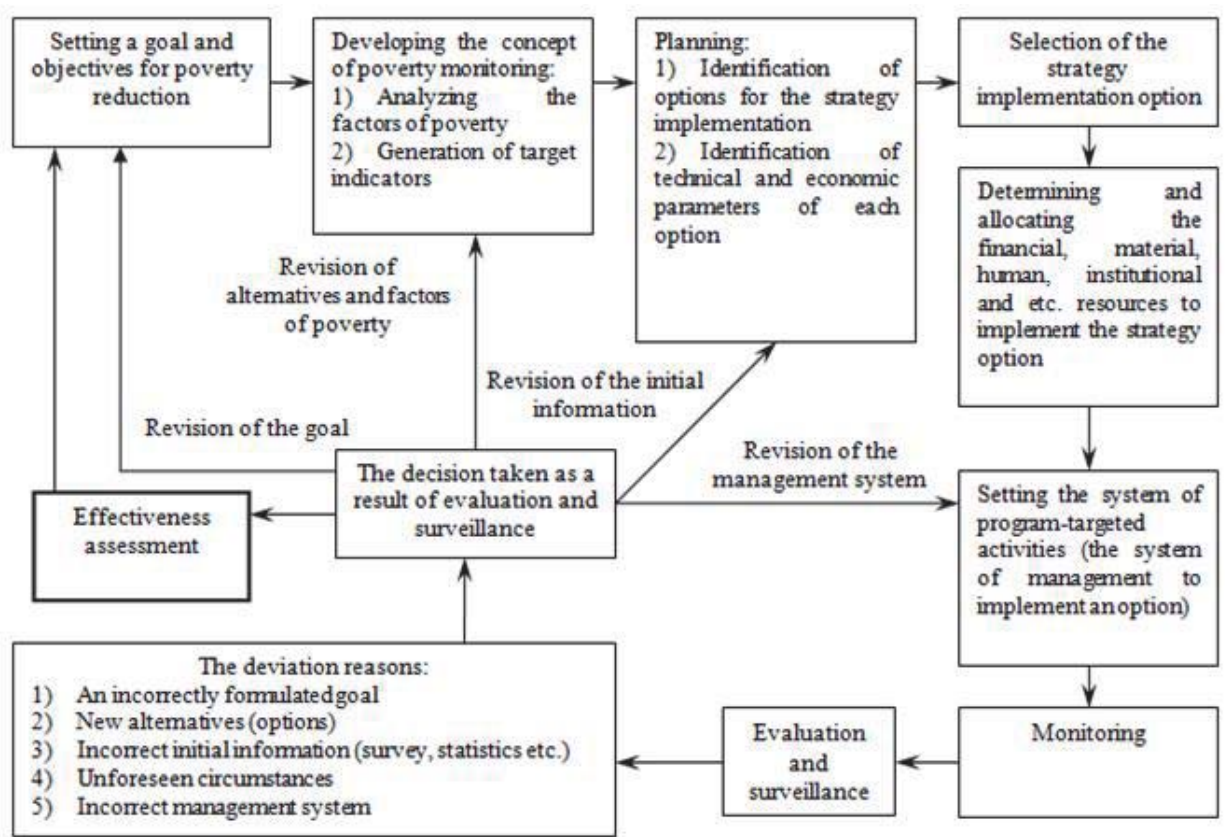

Figure 2. The mechanism of a poverty alleviation strategy implementation

The examination of theoretical foundations for the development of the regional economy and the analysis of socioeconomic differentiation of Russian regions has allowed us to establish the following principles of the poverty alleviation strategy:

1. Ownership. Who does the poverty reduction strategy benefit or impact, and do a sufficient number of these departments and persons feel ownership of the strategy? Rudenko (2011) has proposed the complex model of poverty alleviation in the Tyumen oblast.

2. Democracy. Throughout all stages of planning, monitoring, evaluating, it is vital to engage stakeholders, promote buy-in and commitment, and motivate action. High levels of engagement of users, clients and stakeholders in programmes and projects are critical to success.

3. Relevance. All levels of management hierarchy in the region should be provided only with the necessary information.

4. Result. A strategy implementation should be geared towards ensuring that results are achieved - not towards ensuring that all activities and outputs get produced as planned.

5. Effectiveness. The strategy should contribute to achieve the minimum level of costs and to make the most effective strategic decisions. The authorities must use effective methods of management (result management, bench marketing, strategic planning, target-oriented etc.).

6. Complexity. It is vital to take into account economic, social, environmental and institutional aspects of development and their interrelationship, as any region is an open system.

7. Dynamism. The strategy should be revised on grounds of external or internal conditions have changed.

8. Multiprogramming. Poverty reduction should be implemented on the basis of program-target approach due to the formation of target programs and sub-programs. It is vital to ensure consistency and coherence between programmes. 
9. Multiplicity. The best option should be chosen to achieve the goal and targets depending on the scale of costs, outcomes, and time.

10. Regional identity. There is no single, common poverty reduction strategy for all regions. Each region should develop its own structure of policy measures that reflect local characteristics, initial conditions of socioeconomic development and income inequality. The choice of priorities should be determined by the set of characteristics (economic, social, political, structural, demographic, cultural etc.) of each region and the existing resources.

The range of strategies to reduce poverty is quite large. It is helpful to group them into common categories of activity in accordance with the initial conditions of socio-economic development and income inequality that are very different among Russian regions. Growth is good for the poor, and growth that is accompanied by progressive distributional change is even better. Is the same type of policies appropriate for all Russian regions that want to reduce poverty quickly? For example, should Samara oblast and the Republic of Dagestan which have similar levels of per capita income but are on the opposite sides in terms of income inequality - try to strike a similar balance between growthpromoting and inequality-reducing policies? We are going to answer the question of how do the initial conditions affect the extent of poverty reduction and what type of strategy should we choose.

Poverty and inequality are intrinsically linked. Poverty reduction - especially for the poorest - can be greatly enhanced through distributional policies. Distribution objectives, particularly for assets, should be an integral part of the poverty reduction agenda. But distributional policies can also hurt economic growth, which is essential for sustained poverty reduction. The challenge for regions is how to accelerate it and at the same time make it broad-based for the greater benefit of the poor.

A sensible development strategy should focus both on the quantity of growth (that is, on the achievement of a high growth rate) and on the quality of growth (that is, on who benefits from that growth). There is a question of how much emphasis should policy makers place on achieving a high growth rate and how much on achieving a balanced pattern of growth? What is more advisable from a poverty perspective: a high growth rate that has an associated increase in inequality, or a lower growth rate that maintains inequality at a constant level? It is a very challenging task to design a balanced policy package that incorporates and deals with various trade-offs and promotes growth with equity.

A point of reference for quantifying this trade-off between growth and inequality is brought about by Kakwani (2000), who has developed a methodology to show how much growth is needed in order to offset the adverse impact of an increase in inequality on poverty. This methodology is based on the idea of poverty elasticity with respect to growth and inequality. If $P_{a}$ is any poverty measure, then growth elasticity, denoted by $\eta_{a}$, measures the impact of growth on poverty when inequality does not change. Similarly, inequality elasticity, denoted by $\varepsilon_{a}$, measures the impact of change in inequality on poverty, when the per capita income does not change as well as poverty line remains constant. Then the proportional change in poverty may be written as

$$
\frac{d P_{\alpha}}{P_{\alpha}}=\eta_{\alpha} \frac{d(\mu / z)}{(\mu / z)}+\varepsilon_{\alpha} \frac{d G}{G}=\frac{G r}{P_{\alpha}}+\frac{R}{P_{\alpha}},
$$

where $P_{\alpha}$ is poverty measure, $\mu$ is per capita income, $z$ is poverty line, $\mu / z$ is purchasing power of income or mean income which is expressed as a percentage of the poverty line, $G$ is Gini ratio; $\eta_{a}$ - the growth elasticity of poverty, $\varepsilon_{\alpha}-$ the inequality elasticity of poverty.

The first term on the right-hand side (Gr) measures the impact of growth on poverty, and the second term $(R)$ measures the impact of change in the Gini index on poverty. The first term is always negative, implying that the inequality neutral growth will always reduce poverty. The second term is positive, implying that any increase in inequality resulting from growth will always increase poverty. Thus equating the total proportionate change in poverty to 0 , we obtain the growth-inequality trade-off index as

$$
\varphi_{\alpha}=\frac{d(\mu / z)}{d G} \frac{G}{(\mu / z)}=-\frac{\varepsilon_{\alpha}}{\eta_{\alpha}}
$$

where $\varphi_{a}$ is the growth-inequality trade-off index (GITI).

The index is defined as minus times the ratio of the poverty elasticity of inequality to the poverty elasticity of growth. The trade-off index measures how much growth in per capita income will be required to offset a $1 \%$ increase in inequality, with poverty remaining unchanged. If, for example, GITI is equal to 2.5 , it means that a $1 \%$ increase in the Gini index will require a growth rate of $2.5 \%$ in order to offset the adverse impact of the increase in inequality. Alternatively, if a $1 \%$ fall in the Gini index stems from following some policies, then this strategy is equivalent to having an additional $2.5 \%$ growth rate. This suggests that the larger the GITI, the greater will be the benefits of following the development strategy that would reduce inequality. Hence, the magnitude of GITI can give indication of what development strategy a region 
might consider following. For a region where the trade-off index is small, say less than 1, its policy focus should be on enhancing growth to achieve poverty reduction.

We suggest conducting the algorithm of poverty reduction strategy selection for different types of regions $(A, B, C$, D) as follow: Analysis I, Modeling II, Regulation III and Control IV (Figure 3).

The dependence of the poverty level, average per capita income, and inequality measures should be measured, as well as the poverty elasticity of inequality and the poverty elasticity of growth should be estimated and the growthinequality trade-off index calculated at the first phase (analysis I). The choice of a strategy option is made for groups of regions $(A, B, C, D)$, obtained at the second stage. The priority is determined by the values of the growth-inequality tradeoff index: strategy for reducing inequality dominates the economic growth strategy when the index is higher than 1.

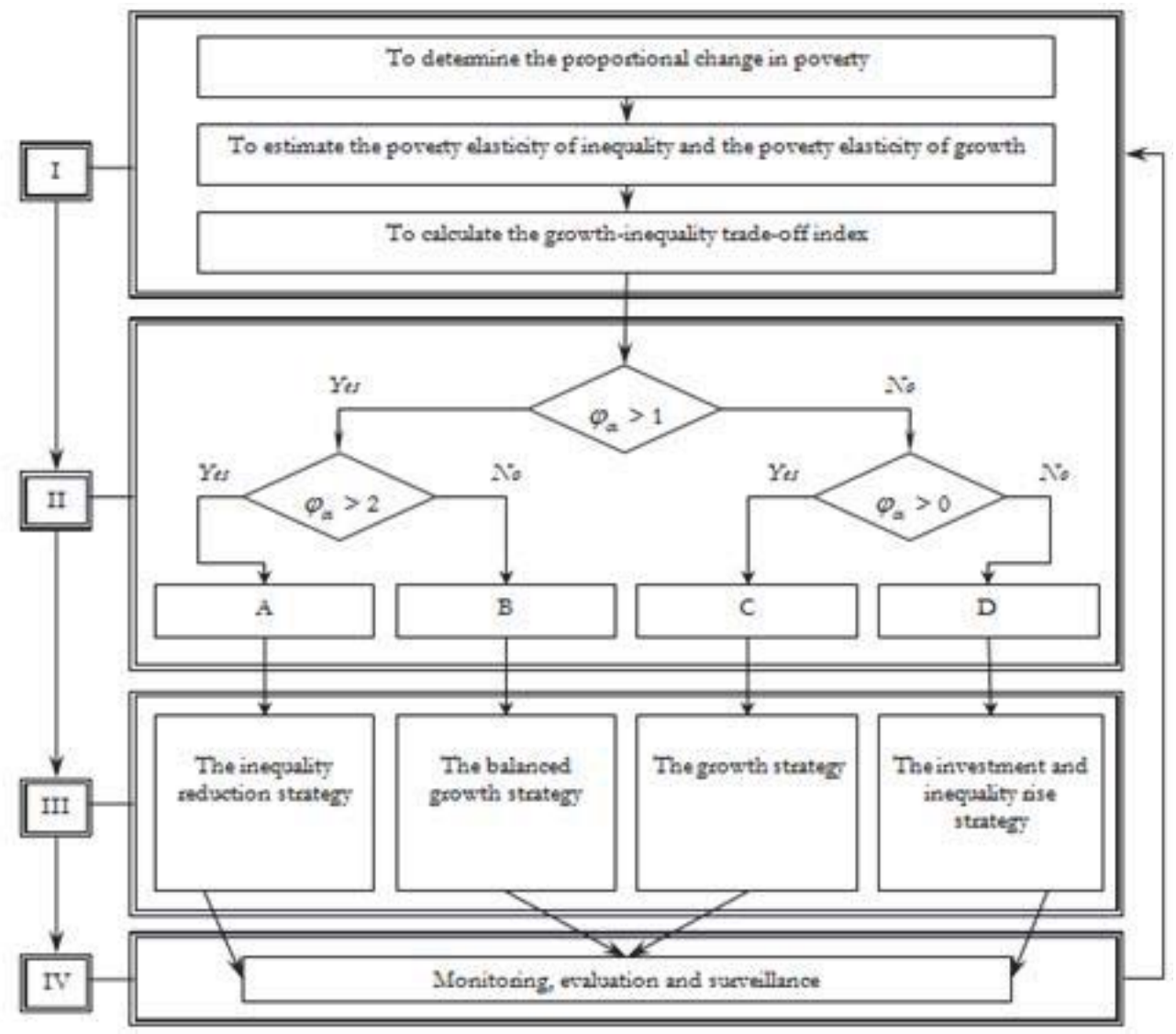

Figure 3. The algorithm of poverty reduction strategy selection depending on the region's model of socio-economic development

Setting the system of program-targeted activities to reduce poverty should be carried out at the stage of regulation taking into account the specifics of each type of region. We distinguish four groups of regions, depending on the initial conditions of socio-economic development.

The type A regions are characterized by a very high level of economic development and the highest inequality. The poor are mainly households with traditional risk - one parent families, the disabled, lonely pensioners of senior age. The growth-inequality trade-off index values indicate the significant dominance of strategies to reduce inequality on economic growth strategies. It is vital to implement the inequality reduction strategy, using the instruments of social protection and redistribution.

The type B regions are characterized by a high level of per capita income, but the level of inequality is lower than in the regions of type $A$. The most effective type of the strategy is a policy of balanced growth, which is implemented in the framework of fighting with social poverty. Program targeted measures of this type regions involve the promotion of opportunities (education, health care etc.). So, distribution policies should be pursued (a) where they remove dysfunctional inequalities, and (b) in regions where the inequality effect on poverty is greater than the growth effect. 
The values of the growth-inequality trade-off index less than 1 for the type $C$ regions indicate to use the strategy of economic growth. Thus, the smaller the value, the more intensive is to promote the highest rates of economic growth excluding the impact of these activities on indicators of inequality. A priority here can be called as a struggle against economic poverty by increasing the labor production, reducing the unemployment, implementing the employment potential of the poor (policy of creating opportunities).

The D-type regions are the poorest, but the most egalitarian regions in which all people are equally poor. The subsistence minimum is higher than the per-capita income that determines the negative poverty elasticity of inequality (in this case, the growth of inequality will reduce poverty). Such a distinguishing feature points to the strategy of increasing inequality and stimulation of investments. The absence of inequality does not provide the concentration of wealth; as a result investment activity in the region's economy is extremely low. It is necessary to form this population group that would become the engine of social and economic changes in the region.

\section{Results}

In this study, we use official data by the Federal State Statistics Service of Russia for 2000-2013 on the average per capita money income and the subsistence minimum, as well as data on the distribution of population by per capita money income.

The headcount ratio is used as the poverty measure, which is the proportion of the population below regional poverty lines. We proceed from the premise that poverty is fully determined by three parameters - the level of per capita income (the mean income of the distribution), the poverty line and the Lorenz curve representing the structure of relative income inequalities. The poverty index, as measured by the class of FGT indices, can be written as

$$
P_{\alpha}=P(L, \mu / z) \text {, }
$$

where $P_{\alpha}$ - the poverty index, $\mathrm{L}-$ a vector of parameters fully describing the Lorenz curve, $\mu$ - the (average income, $z$ - the poverty line.

The framework of analysis has its origins in the decomposition of changes in poverty into growth and redistribution components proposed by Ravallion and Datt. The level of poverty may change due to a change in the mean income $\mu / z$, or due to a change in relative inequalities (1).

Since initial conditions in all regions are quite different, their poverty elasticities vary widely. We have computed the poverty elasticity for each region to calculate the growth-inequality trade-off indices. These calculations have been done under the assumption that the per capita income follows a two-parameter lognormal distribution. As an analytical tool we used the interpolation method, supposing the selection of an empirical distribution curve for the given income ranges by the OLS method and the calculation of the necessary values of the poverty based on the selected curve, presented in the work of Kolenikov and Shorrocks (2003). The advantage of this technique of parameterization of poverty indices is that by having the data on the income distribution by groups of the population (deciles or quintiles), the poverty line, and the average income level in the region, one can easily simulate any poverty indicators and decompose poverty changes into growth and redistribution effects.

According to the values of the growth-inequality trade-off index we have classified Russian Arctic regions into four groups as presented in table 4.

We have found that the growth-inequality trade-off index increases monotonically with the level of income. This indicates greater effectiveness of distribution policies in regions with higher incomes than in regions with lower incomes. As mean income rises, the poverty elasticity of inequality increases at a faster rate than the poverty elasticity of growth. The relative importance of growth and distribution varies across Russian Arctic regions.

Table 4. A typology of poverty reduction strategies in the Russian Arctic regions

\begin{tabular}{|l|l|c|}
\hline Type of a strategy & Regions & Number \\
\hline The investment and inequality rise strategy (type D) & None & 0 \\
\hline The growth strategy (type C) & $\begin{array}{l}\text { None (But this strategy should be implemented in } \\
\text { Republic of Tyva or Kalmikia, not Arctic regions) }\end{array}$ & 0 \\
\hline The balanced growth strategy (type B) & $\begin{array}{l}\text { Chukotka, Murmansk Oblast, Komi Republic, } \\
\text { Arkhangelsk Oblast, Krasnoyarsk Oblast, Yakutia }\end{array}$ & 6 \\
\hline The inequality reduction strategy (type A) & $\begin{array}{l}\text { Yamal-Nenets Autonomous Okrug, Nenets } \\
\text { Autonomous Okrug }\end{array}$ & 2 \\
\hline
\end{tabular}


The level of, and changes in, inequality are key determinants of whether regions, especially Yamal-Nenets Autonomous Okrug and Nenets Autonomous Okrug, will reduce poverty. Regional authorities should fight against social poverty and try to avoid further increasing of inequality in six Arctic regions of type B (Yakutia, Chukotka and etc.). The strategy of economic growth and inequality rise strategy should be implemented in none regions

\section{Concluding Remarks}

We have demonstrated analytically that the initial levels of economic development and income inequality matter for the reduction of poverty. The methodology presented in the paper helps us to make a policy choice between proposed types of poverty reduction strategies. We have proved that the poverty indicators in the relatively rich regions and regions with high inequality are more sensitive to changes in distribution than changes in average income. At the same time, the poverty level in the regions with low income and relatively low inequality stronger responsive to economic growth than to changes in inequality. The author comes to the conclusion that the poverty reduction strategy should include a greater tendency to stimulate growth (even at the expense of inequality) in the regions with low income and relatively low inequality. While in wealthy regions or regions with excessive inequality policy should be sufficient to balance the goals of growth and the goal of reducing inequality. The proposed mechanism of a poverty alleviation strategy implementation as well as the algorithm of its selection, in our opinion, are of great practical importance, since they can be used by the regional and local authorities when developing measures for socio-economic development, the continuous monitoring of poverty, amendments to the adopted strategies.

\section{Acknowledgement}

This paper is based on the research carried out with the financial support of the grant of the Russian Scientific Foundation (project №14-38-00009).

\section{References}

Aivazyan, S.A. (1997). The model for the formation of population distribution in terms of per capita income in Russia. Economics and Mathematical Methods, (4), 74-86.

Kakwani, N. (2000). Growth and poverty reduction: An empirical analysis. Asian Development Review, 18 (2), 74-84.

Kakwani, N., \& Pernia, E. (2000). What is pro-poor growth? Asian Development Review, 18 (1), 1-16.

Kolenikov, S.O., and Shorrocks, A.F. (2003). A decomposition analysis of regional poverty in Russia. <http://www.wider.unu.edu/stc/ repec/pdfs/rp2003/dp2003-74.pdf>. (accessed May 30, 2014).

Meyer, D.F. (2014). The Impact of Housing and Basic Service Delivery on Low-Income Communities in South Africa: The Case of the northern Free State Region. Mediterranean Journal of Social Sciences, 5 (13), 11-20. Doi:10.5901/mjss.2014.v5n13p11

Meyer, D.F. (2014). The Influence of the Provision of Basic Needs on Participation in Sport in a Poor Community: The Case of Sicelo. Mediterranean Journal of Social Sciences, 5 (23), 2243-2251. Doi:10.5901/mjss.2014.v5n23p2243

Olaniyi, F.O., and Aroge S.T. (2014). Poverty Alleviation Strategies in Nigeria: The Missing Link of Adult Education. Mediterranean Journal of Social Sciences, 5 (23), 1674-1679. Doi:10.5901/mjss.2014.v5n23p1674

Ravallion, M. \& Chen, S. (2003). Measuring pro-poor growth. Economics letters, 78 (1), 93-99.

Rosstat (2014). Social and Economic Indicators for Russia's Regions 2013. < http://www.gks.ru/bgd/regl/b13_14p/Main.htm> (accessed November 10, 2014).

Rudenko, D.Y. (2011). The complex systematization model of poverty alleviation in the Tyumen Region. Tyumen State University Herald, (11), 127-136.

Rudenko, D.Y. (2014a). Alternative Approaches to Measure Poverty in Russian Regions. Mediterranean Journal of Social Sciences, 4 (13), 262-267. Doi:10.5901/mjss.2014.v5n13p262

Rudenko, D.Yu. (2014b). A comprehensive approach to the study of poverty in the region. Regional research of Russia, 4 (3), 141-149. Doi: 10.1134/S2079970514030083

Son H. \& Kakwani N. Economic Growth and Poverty Reduction: Initial Conditions Matter. Working Paper № 2. Brasilia: UNDP International Poverty Centre, 2004. <http://www.ipc-undp.org/pub/IPCWorkingPaper2.pdf>, (accessed May 30, 2014). 